\title{
Finanças, fundo público e financiamento da Seguridade Social no Brasil
}

\author{
Osmar Gomes Alencar Junior \\ Universidade Federal do Piauí (UFPI)
}

\author{
Evilasio da Silva Salvador \\ Universidade de Brasília (UnB)
}

\section{Finanças, fundo público e financiamento da Seguridade Social no Brasil}

Resumo: O artigo analisa os efeitos produzidos pela hegemonia neoliberal das finanças sobre o financiamento tributário da política pública de Previdência Social, Saúde e Assistência Social durante o governo Lula no Brasil. Utilizou referencial teórico de tradição marxista e analisou os dados do Orçamento Geral da União retirados do sistema SIGA Brasil do Senado Federal sobre as fontes de recursos da seguridade social. Conclui que os trabalhadores contribuíram mais do que os capitalistas no financiamento tributário da seguridade social no governo Lula.

Palavras-chave: Finança. Fundo Público. Seguridade Social.

\section{Finances, Public Fund and Financing of Social Security in Brazil}

Abstract: This article analyzes the effects produced by the neoliberal hegemony of finance over the tax financing of public policy for social security, healthcare and social assistance during the Lula government in Brazil. It uses traditional Marxist theoretical references and analyzed federal budget data found in the federal Senate SIGA system about the sources of funding for social security. It concludes that workers contribute more than capitalists in the tax financing of social security in the Lula government.

Keywords: Finance. Public Fund. Social Security. 


\section{Introdução}

A passagem entre o século 20 e o 21 foi marcada por mudanças no Estado capitalista, tanto de caráter ideológico, com o protagonismo das ideias neoliberais, quanto econômico, com a dominância das finanças (capital financeiro ou capital portador de juros) sobre o processo de produção e reprodução do capital. Para os autores de tradição marxista, estas mudanças são parte de uma reação burguesa à crise estrutural do capital, no qual a superprodução é sua raiz e a queda da taxa média de lucros é seu fruto (MESZÁROS, 2009). Essa crise de lucratividade é engendrada a partir do final dos "anos gloriosos", quando o crescimento econômico da maioria dos países avançados é reduzido drasticamente e a demanda por bens e serviços, principalmente os públicos, cresceram na forma de direitos sociais conquistados pela classe trabalhadora e implementados pelo Estado.

Para combater a crise estrutural de superprodução e a queda da taxa de lucros, o capital reage ampliando a exploração da força de trabalho, exportando capitais para os países demandantes de mercadorias e diminuindo os investimentos nas atividades produtivas para reinvestir em atividades financeiras. Os anos 1980-1990 deixaram evidente a resposta do capital, principalmente, na forma da reestruturação produtiva, das finanças mundializadas, do ajuste neoliberal do Estado e na ofensiva ao trabalho e suas formas de organização e de luta.

Em um contexto de reação burguesa à crise do capital, este artigo propõe discutir a hegemonia neoliberal das finanças no capitalismo contemporâneo e seus efeitos nas políticas públicas de países periféricos latinoamericanos. Nesse sentido, a questão central busca analisar os efeitos da financeirização e do ajuste estrutural do Estado no fundo público e nas fontes de financiamento das políticas de saúde, previdência e assistência social no governo Lula.

Para responder essa questão buscamos analisar a centralidade do neoliberalismo e do capital financeiro no Estado capitalista contemporâneo, bem como as repercussões no fundo público e nas fontes de financiamento da seguridade social no governo Lula. Para tanto, utilizamos fontes de dados como: Orçamento Geral da União, Balanço Geral da União disponíveis no sistema de informações SIGA Brasil do Senado Federal, e analisamos a importância relativa de cada fonte de financiamento nos gastos da seguridade social.

\section{A centralidade da ideologia neoliberal e da finança no estado capitalista contemporâneo}

Para os críticos de tradição marxista contemporânea, os anos 1970 marcaram o início de uma reação burguesa à crise do capital - queda da taxa de lucros - que buscou reconfigurar o papel do Estado capitalista nas décadas seguintes com forte impacto nas políticas sociais. Essa reação se configurou, principalmente, em três movimentos conjuntos: de reestruturação produtiva, de mundialização do capital com dominância financeira e de ajuste estrutural (neoliberal) do Estado (BEHRING, 2008).

O primeiro movimento teve como base a revolução tecnológica e organizacional da produção. Esgotouse o rígido processo produtivo fordista/taylorista baseado na linha de montagem mecanizada, organização verticalizada, em salários e consumo dos trabalhadores mais elevados garantidos por acordos coletivos de trabalho e por um sistema de proteção social estatal. Ergue-se o toyotismo, processo de produção flexível, automatizado, horizontalizado e descentralizado baseada em tecnologias intensivas de capital e flexibilizadoras de mão de obra. A reestruturação produtiva ou período de acumulação flexível, segundo Harvey (1993), buscou reduzir a tendência de queda da taxa de lucro nos anos 1980 e 1990 por meio do aumento da produtividade do trabalho com reduzidos custos a partir do que Behring (2008, p. 40) chama de um "processo de superexploração da força de trabalho para ampliar a taxa de mais-valia e de lucro" para os capitalistas. Isto ocorre sem qualquer preocupação com as consequências produzidas, por exemplo, pelo desemprego crônico e estrutural dos trabalhadores.

O segundo teve como base a mundialização da economia, a liberalização financeira e a desregulamentação das finanças. Aglietta (2004) revela que a partir dos anos de 1980 ocorreu uma forte expansão financeira, paralelamente à desaceleração do crescimento econômico nos países desenvolvidos. O novo ambiente financeiro foi propício para acumulação patrimonial das famílias mais ricas. Conforme o autor, a desregulamentação das finanças possibilitou um redirecionamento do capital financeiro canalizado pelos investidores institucionais (fundos de pensão, fundos coletivos de aplicação, sociedades de seguros, bancos que administram sociedades de investimento) que foram forçados pela concorrência a realizar administrações mais dinâmicas das carteiras que lhes eram confiadas, isto é, com maior grau de especulação financeira. A liberalização financeira pavimentou o caminho para acumulação da riqueza privada de forma mais rápida que em outras épocas do capitalismo.

Contudo, a riqueza não veio por meio da economia real, ou seja, pela produção de novos bens e serviços, já que a taxa de crescimento da produção decresceu sensivelmente a partir de meados dos anos 1970. A riqueza foi resultado de uma inflação do preço dos ativos reais (terrenos urbanos e propriedades imobiliárias) e 
financeiros (ações), que cresceram acima da média dos preços da economia, o que tornava insustentável esse padrão, pois era incompatível com os fluxos de rendimentos futuros.

As finanças não são neutras, pois elas influenciam a alocação de poupança entre esses dois tipos de aplicação. Em conjuntura de crescimento endógeno, implica o deslocamento da poupança para aplicações improdutivas, afetando desfavoravelmente o crescimento econômico. "As mais-valias esperadas das transferências de propriedade desencorajam as apostas das empresas na inovação e forçam a taxa de juros real a elevar-se acima do nível que torna o rendimento sobre os créditos competitivos com o dos ativos especulativos" (AGLIETTA, 2004, p. 29).

Conforme Chesnais (1996), a mundialização do capital indica a capacidade estratégica de todo grande grupo oligopolista voltado para a produção manufatureira ou para as principais atividades de serviços de adotar, por conta própria, um enfoque e condutas "globais". Assim como na esfera financeira, a integração internacional é o corolário da liberalização e da desregulamentação que levaram à abertura dos mercados nacionais e permitiram sua integração em tempo real. O desenvolvimento desses mercados especulativos permitiu um enriquecimento privado sem encorajar o investimento produtivo. Aglietta $(2004$, p. 27) destaca que nos anos 1980 ocorre uma "orientação da poupança rumo aos investidores institucionais, graças ao desenvolvimento de regimes de aposentadoria por capitalização em numerosos países, estimulados pelas perspectivas do envelhecimento demográfico".

Para Chesnais (2005), o agravamento das taxas de superexploração capitalista - da questão social realizada pela reestruturação produtiva, não ocupa a centralidade nas relações econômicas e sociais nos novos tempos do capital. Esta é ocupada, atualmente, pelo capital portador de juros (capital financeiro ou finança). Mas, o que significa capital portador de juros? Para Marx (1988, p. 245), era o capital que se valorizava fora do processo produtivo. Na sua forma ordinária:

O possuidor de dinheiro que quer valorizar seu dinheiro como capital portador de juros aliena-o a um terceiro, lança-o na circulação, torna-o mercadoria como capital; não só como capital para si mesmo, mas também para outros; não é meramente capital para aquele que o aliena, mas é entregue a terceiro de antemão como capital, como valor que possui o valor de uso de criar mais-valia, lucro.

No mundo contemporâneo, o capital portador de juros manteve suas raízes e ampliou as formas de captação de valores. É o “capital que busca 'fazer dinheiro' sem sair da esfera financeira, sob a forma de juros de empréstimos, de dividendos e outros pagamentos recebidos a título de posse de ações e, enfim, de lucros nascidos de especulação bem-sucedida" (CHESNAIS, 2005, p. 35). No entanto, é reconhecido também como finança a "fração superior das classes capitalistas e as instituições onde se concentra sua capacidade de ação" (DUMMÉNIL; LÉVY, 2005, p. 87). A finança se reconstituiu a partir da acumulação financeira de organizações capitalistas já consolidadas, como as indústrias transnacionais/sociedades transnacionais, instituições financeiras bancárias e, principalmente, não bancárias. Estas buscam valorizar seu capital na esfera financeira, tendo como campo de atuação os mercados financeiros liberalizados e interconectados local e mundialmente. Suas operações interbancárias estão vinculadas ao mercado de créditos e de títulos da dívida pública (CHESNAIS, 2005).

A importância do capital portador de juros no mundo capitalista emerge, novamente, nos anos 1980 e 1990 junto com instituições especializadas em maximizar o valor acionário, os investidores institucionais. Esquecida no período do predomínio do arranjo keynesiano-fordista, a finança passa a engendrar nos países capitalistas avançados um regime de acumulação com dominância financeira, que se caracteriza pela "centralização em instituições especializadas de lucros industriais não reinvestidos e de rendas não consumidas, que tem por encargo valorizá-los sob a forma de aplicação em ativos financeiros - divisas, obrigações e ações mantendo-os fora da produção de bens e serviços" (CHESNAIS, 2005, p. 37).

É um processo de acumulação exterior à produção de bens e serviços e interior à esfera financeira, em que o capital portador de juros foi alçado para o centro das relações econômicas e sociais pelas medidas de liberalização monetária e desregulamentação financeira, realizados pelos governos dos países mais desenvolvidos, principalmente, Estados Unidos e Inglaterra, no período 1979-1981. Essas medidas buscavam retirar qualquer controle sobre o movimento de capitais e destravar os sistemas financeiros nacionais para investimentos estrangeiros. Junto com elas, duas outras medidas, a descompartimentalização dos mercados financeiros nacionais e a desintermediação, contribuíram para o "nascimento do sistema de finança mundializada tal como o conhecemos" (CHESNAIS, 2005, p. 44).

O terceiro movimento foi o ajuste neoliberal do Estado. Os anos 1940 aos 1970 marcaram um período de forte crescimento da economia mundial, principalmente para os países capitalistas mais desenvolvidos. No campo econômico, foram trinta anos de crescimento sustentado pelo regime de acumulação keynesiano-fordista, 
que produziu "forte expansão da demanda efetiva, altas taxas de lucro, elevação do padrão de vida das massas no capitalismo central, e um alto grau de internacionalização do capital" sob a dominação econômica dos Estados Unidos (BEHRING; BOSCHETTI, 2011, p. 88).

No campo político, a sustentação do crescimento duradouro foi forjado pelo amplo acordo entre o capital e o trabalho organizado.

Para burguesia, a manutenção de altas taxas de lucros, fundada numa superexploração dos trabalhadores durante um intervalo estável de tempo, pressuponha concessões e acordos. Para o movimento operário organizado, essa possibilidade histórica implicou abrir mão de um projeto mais radical, em prol de conquistas e reformas imediatas, incluindo-se aí os direitos sociais, viabilizados pelas políticas sociais (BEHRING; BOSCHETTI, 2011, p. 88).

No campo social, o crescimento é assegurado via ampliação dos gastos públicos sociais por meio da instituição de serviços e políticas sociais pelo Estado com a finalidade de criar demanda e ampliar o mercado de consumo. A partir de então, o Estado passou a intervir e a conduzir a recuperação e o crescimento econômico dos países desenvolvidos por meio de estímulos à demanda efetiva via políticas públicas econômicas (fiscal e monetária) e sociais expansivas e pela realização de investimentos ou inversões reais. Entretanto, o forte crescimento da economia dos países centrais no segundo pós-guerra minou a expansão dos ideais neoliberais que desde 1944, com Friedrich Hayeck, se manifestavam contra o intervencionismo estatal e o Estado de bem estar. Mas a crise do início dos anos 1970, principalmente a partir do choque do petróleo, deu margem para que as ideias neoliberais se proliferassem. O quadro revela as limitações das políticas keynesianas diante da internacionalização do capital, com sinais de esgotamento do padrão de financiamento das políticas sociais e a reação do capital à queda das taxas de lucro na sua sanha pela acumulação e, portanto, por superlucros. Os capitalistas se armam para revogar as conquistas sociais do pacto socialdemocrata investindo contra os trabalhadores, em busca de restabelecer um novo padrão de acumulação para saída da crise. O desenvolvimento de novas tecnologias aumenta a composição orgânica do capital, reforçando a tendência decrescente da taxa de lucros. Para Mandel (1982), como a força de trabalho está reduzida em relação à reprodução automatizada, ocorre uma queda no valor unitário das mercadorias, desvalorizando o capital. Há uma superprodução global, aumentando o excedente, o que corrobora para a crise clássica do capitalismo, elevando a possibilidade de estagnação.

Os novos investimentos, para atender à demanda, elevam a capacidade produtiva, chegando ao apogeu com a realização da produção. Mas o sistema capitalista não funciona em equilíbrio. Assim, quando a expansão se encerra e a capacidade ociosa surge, não há realização do consumo. A produção de mercadorias para além do seu valor de uso entra em choque com sua realização enquanto valor de troca, gerando uma crise de superprodução (MANDEL, 1982). A crise se manifesta juntamente com a reação do capital contra o Estado Social. A onda de expansão do capitalismo expõe também a contradição do próprio sistema e o avanço tecnológico com uso intensivo de capital vem acompanhado de economias com a força de trabalho, solapando o pacto dos anos de crescimento com pleno emprego e o arranjo da social democracia para as políticas sociais. A inflação a partir dos anos 1970 é um desestímulo ao aquecimento da demanda global e incentivadora da especulação financeira. A recessão após 1974 põe fim ao sonho de que a crise do capitalismo seria contornável por políticas de cunho keynesiano (MANDEL, 1990).

A hegemonia do neoliberalismo só ocorreu no final dos anos 1970, quando EUA e Inglaterra adotaram nos seus programas governamentais os princípios neoliberais reformistas para debelar a crise. A hegemonia foi reforçada, em 1989, com o Consenso de Washington, quando os países da América Latina, para receberem recursos internacionais na forma de empréstimos ou investimentos produtivos do capital financeiro ou das multinacionais, teriam que se submeterem a ajustes estruturais (neoliberais) no Estado, por meio de um plano de estabilização e reforma econômica aprovado pelo FMI e BID. Os ajustes neoliberais seriam o passaporte para a inserção dos países periféricos, principalmente os da América Latina, no capitalismo contemporâneo. Neste contexto de hegemonia neoliberal das finanças, como a América Latina, em particular o Brasil, se insere na dinâmica da mundialização do capital (mundialização financeira) a partir dos anos 1990 ?

As décadas de 1980 e 1990 foram marcadas pela difusão de uma ideologia neoliberal que atrelava a recuperação do atraso e o crescimento econômico dos países em desenvolvimento (PED) a uma maior integração destas na economia mundial por meio de um ingresso importante de capitais privados externos. Havendo assim, uma "relação positiva entre a participação crescente de um país (ou de uma região) no processo de globalização financeira e a aceleração de seu desenvolvimento econômico" (CAMARA; SALAMA, 2005, p. 200).

Portanto, um país estaria mais integrado financeiramente no mercado mundial ou mais conectado aos mercados financeiros internacionais na medida em que não houvesse entraves para a movimentação de capitais e, portanto, os recursos da poupança de um país não fossem atrelados a investimentos internos, podendo 
ser direcionados a aplicações mais vantajosas em qualquer região do planeta. Neste contexto de mundialização financeira, isto é, de aumento dos fluxos de capitais entre os países e de inserção dos PED na economia mundial, a inserção financeira da América Latina ocorre principalmente sob a forma de empréstimos bancários (2/3 do total), sendo o setor público dos países nacional-desenvolvimentistas o grande beneficiário nos anos 1970. Porém, nos anos 1980, com a elevação das taxas de juros, a crise da dívida se instala nos PED e são reduzidos drasticamente os fluxos de capitais internacionais em sua direção (CAMARA; SALAMA, 2005).

No Brasil, os anos 1980 são conhecidos como a década perdida, do ponto de vista econômico, mas de grandes conquistas sociais em face das lutas democráticas e da Constituição de 1988. O recrudescimento do endividamento externo com o aumento das taxas de juros internacionais no "golpe de 1979", provocando a crise da dívida dos anos 1980 e a queda nas exportações de matérias-primas, estrangulou a economia brasileira. O investimento público caiu 10\% em 16 anos (1974-1989), a dívida contraída pelo setor privado, sob pressão do FMI, foi amplamente estatizada pelo governo brasileiro, sendo que "70\% da dívida externa tornou-se estatal" (BEHRING; BOSCHETTI, 2010, p. 139). O fluxo de capitais externos para o país reduziu pela metade.

Diante deste cenário de déficits e de redução drástica dos investimentos externos, o governo brasileiro decidiu financiar suas dívidas por meio de emissão de títulos públicos a juros atraentes alimentando o processo inflacionário. A manipulação da taxa de juros torna-se a variável central na política econômica brasileira, pois passa a ser utilizada para equilibrar entrada e saída de capitais, o balanço de pagamentos. No entanto, as altas taxas de juros são fundamentais, mas não garantem a atração de capitais externos para financiar possíveis déficits públicos. Em compensação, produzem um efeito perverso internamente: o aumento da vulnerabilidade dos bancos; a elevação dos custos dos empréstimos; o aumento dos déficits orçamentários não acompanhados pela redução das despesas públicas; e a elevação demasiada da vulnerabilidade social - desemprego, miséria, concentração de renda e redução dos gastos sociais (CAMARA; SALAMA, 2005). A lógica financeira introduzida na economia brasileira combinada com o ajuste neoliberal do Estado nos governos Collor-ItamarFHC, produziram quais efeitos no financiamento tributário das políticas de seguridade social - saúde, previdência e assistência social - no governo Lula?

\section{Fundo público e financiamento tributário das políticas de seguridade social no Brasil}

No Brasil, a Constituição de 1988 estabeleceu, no artigo 194, que a seguridade social compreende um conjunto integrado de ações de iniciativa dos poderes públicos e da sociedade, destinado a assegurar os direitos relativos à saúde, à previdência e à assistência social, tendo como princípios a universalidade, diversidade da base de financiamento, o caráter democrático e descentralizado da administração e gestão participativa, dentre outros. A política de seguridade social passaria a ser financiada anualmente por toda a sociedade, indistintamente, de forma direta e indireta, na forma da lei, mediante recursos provenientes dos orçamentos da União, Estados, Distrito Federal e dos Municípios e de contribuições sociais do empregador, trabalhador e sobre a receita de concursos de prognósticos (BRASIL, 1988). O estabelecimento de fontes de financiamento, a partir de 1988, assegurou, constitucionalmente, recursos para a implantação das políticas sociais brasileiras, ampliando a importância do fundo público e do Estado brasileiro na resolução dos conflitos sociais e econômicos advindos do modo de produção capitalista. O fundo público passou a assumir cada vez mais importância no capitalismo contemporâneo e está presente na reprodução do capital e da força de trabalho, conforme Salvador (2010), das seguintes maneiras: a) como fonte importante para a realização do investimento capitalista, por meio de subsídios, de desonerações tributárias, por incentivos fiscais e pela redução da base tributária da renda do capital; b) viabilizando a reprodução da força de trabalho, por meio de salários indiretos, reduzindo custo do capitalista na sua aquisição; c) assegurando recursos orçamentários para investimentos em meios de transporte e infraestrutura, nos gastos com investigação e pesquisa, além dos subsídios e renúncias fiscais para as empresas; e, d) transferindo recursos sob a forma de juros e amortização da dívida pública para o capital financeiro, em especial para a classe dos rentistas.

O fundo público envolve toda a capacidade de mobilização de recursos que o Estado tem para intervir na economia, seja por meio das empresas públicas, pelo uso das suas políticas monetária e fiscal, assim como pelo orçamento público (SALVADOR, 2012). Para Behring (2010), isso só é possível por meio de extração compulsória - na forma de impostos, contribuições e taxas - da mais-valia socialmente produzida, ou seja, o fundo público é financiado a partir de parte do trabalho excedente que metamorfoseou em lucro, juro ou renda da terra e que é apropriado pelo Estado para o desempenho de suas múltiplas funções. O instrumento dessa punção é o sistema tributário, sistema que financia as políticas sociais implementadas pelo Estado com a finalidade de garantir, minimamente, as condições de reprodução da força de trabalho e de continuidade do processo de acumulação capitalista. 
Entretanto, o instrumento mais objetivo do fundo público é o orçamento público, mais do que uma peça técnica de planejamento é uma arena de disputa política na qual o direcionamento dos gastos e suas respectivas fontes de financiamentos refletirão, mais do que uma decisão econômica, as correlações de forças sociais e políticas hegemônicas na sociedade.

Apesar da Constituição brasileira de 1988 ter avançado na garantia dos direitos de cidadania - Saúde, Previdência Social, Assistência Social e outros -, sua institucionalização se deu em momento de crise do capital com predomínio da ideologia neoliberal e da contrarreforma do Estado, sendo extremamente difícil colocar recursos orçamentários necessários para financiar as mudanças propostas pela Constituição. Além da dificuldade da expansão dos recursos orçamentários para a efetivação dos direitos sociais previstos na Constituição de 1988, a regressividade da carga tributária - onerando fiscalmente os mais pobres e privilegiando os mais ricos - característica central do sistema tributário brasileiro, dificultou mais ainda a velocidade da sua expansão.

No governo FHC, por exemplo, houve um aprofundamento do caráter regressivo da carga tributária, como consequência "uma perversa concentração de renda via financiamento do orçamento público", e seu caráter não fora modificado no governo Lula (SALVADOR, 2012, p. 129). Esse caráter regressivo da carga tributária, mantida no governo Lula, fica mais evidente quando são analisadas as fontes de financiamento das políticas de seguridade social no Brasil. O custeio da seguridade social tem sido realizado de forma fragmentada, contrariando o princípio da totalidade ${ }^{1}$ expresso na Constituição de 1988. Desde a implantação do Plano Real, os recursos das contribuições sociais diretas dos empregadores e trabalhadores financiam, exclusivamente, os gastos da previdência social enquanto os recursos das contribuições sobre o faturamento, os lucros e a movimentação financeira financiam os gastos com saúde e assistência social (SALVADOR, 2012). Os dados da Tabela 1 revelam as principais fontes de financiamento da seguridade social, no período analisado.

Tabela 1 - Financiamento da Seguridade Social por fonte de recursos no período de 20032010, em R\$ milhões constantes, deflacionados pelo IGP-DI

\begin{tabular}{|c|c|c|c|c|c|c|c|c|c|c|c|}
\hline FONTES & 2003 & 2004 & 2005 & 2006 & 2007 & 2008 & 2009 & 2010 & média & part \% & $\operatorname{var} \%$ \\
\hline $\begin{array}{l}\text { Recursos Proveni- } \\
\text { entes de Impostos }\end{array}$ & 33.450 & 21.365 & 19.656 & 14.494 & 20.138 & 37.566 & 39.264 & 33.612 & 27.443 & 6,81 & 0,48 \\
\hline $\begin{array}{l}\text { Contribuições } \\
\text { Sociais }\end{array}$ & 317.353 & 307.632 & 322.701 & 353.035 & 377.666 & 391.815 & 401.727 & 418.808 & 361.342 & 89,68 & 31,97 \\
\hline Outras Fontes & 4.436 & 4.529 & 4.206 & 4.949 & 5.357 & 5.682 & 5.102 & 37.409 & 8.959 & 2,22 & 743,30 \\
\hline $\begin{array}{l}\text { Fundo de Comba- } \\
\text { te a pobreza }\end{array}$ & 2.197 & 7.836 & 7.267 & 9.000 & 12.340 & 2.854 & 80 & 20 & 5.199 & 1,29 & $-99,09$ \\
\hline TOTAL & 357.436 & 341.362 & 353.830 & 381.478 & 415.501 & 437.917 & 446.173 & 489.849 & 402.943 & 100,00 & 37,05 \\
\hline
\end{tabular}

Fonte: Salvador (2012). Elaboração dos autores.

No governo Lula, em 2003, as receitas oriundas de diversas fontes de recursos para financiar a seguridade social totalizaram $R$ \$ 357.436 milhões. As contribuições sociais participaram com $R$ \$ 317.353 milhões, seguidas por recursos provenientes impostos de $\mathrm{R} \$ 33.450$ milhões, outras fontes $\mathrm{R} \$ 4.436$ milhões e o fundo de combate à pobreza $\mathrm{R} \$ 2.197$ milhões, como pode ser visualizado na Tabela 1.

Apesar do declínio das contribuições sociais em 2004, quando descontado a inflação do período, nos outros seis anos de governo houve aumentos sistemáticos no volume de recursos aportados, atingindo $\mathrm{R} \$ 418.808$ milhões em 2010. As outras fontes (incluso receitas financeiras e outros recursos) atingiram $\mathrm{R} \$ 37.409$ milhões, as receitas provenientes de impostos $\mathrm{R} \$ 33.612$ milhões e as do fundo de combate à pobreza $\mathrm{R} \$ 20$ milhões.

No governo Lula (2003-2010), as contribuições sociais cresceram 31,97\% e foram responsáveis, em média, por $89,68 \%$ dos recursos aportados no financiamento da seguridade social, enquanto os recursos provenientes de impostos praticamente não cresceram e os do fundo de combate à pobreza pouco acrescentaram. No entanto, os recursos de outras fontes tiveram um crescimento explosivo de 743,3\%, influenciado por novas receitas (receitas financeiras, operações de crédito e outros recursos), porém sua participação média foi de 2,22\%.

O gráfico 1, abaixo, possibilita uma visualização do crescimento das contribuições sociais no período de 2003 a 2010, no financiamento da seguridade social. 
Gráfico1 - Receitas de Contribuições Sociais distribuídos por subfontes de recursos no período 2003-2010, em R\$ milhões constantes, deflacionados pelo IGP-DI

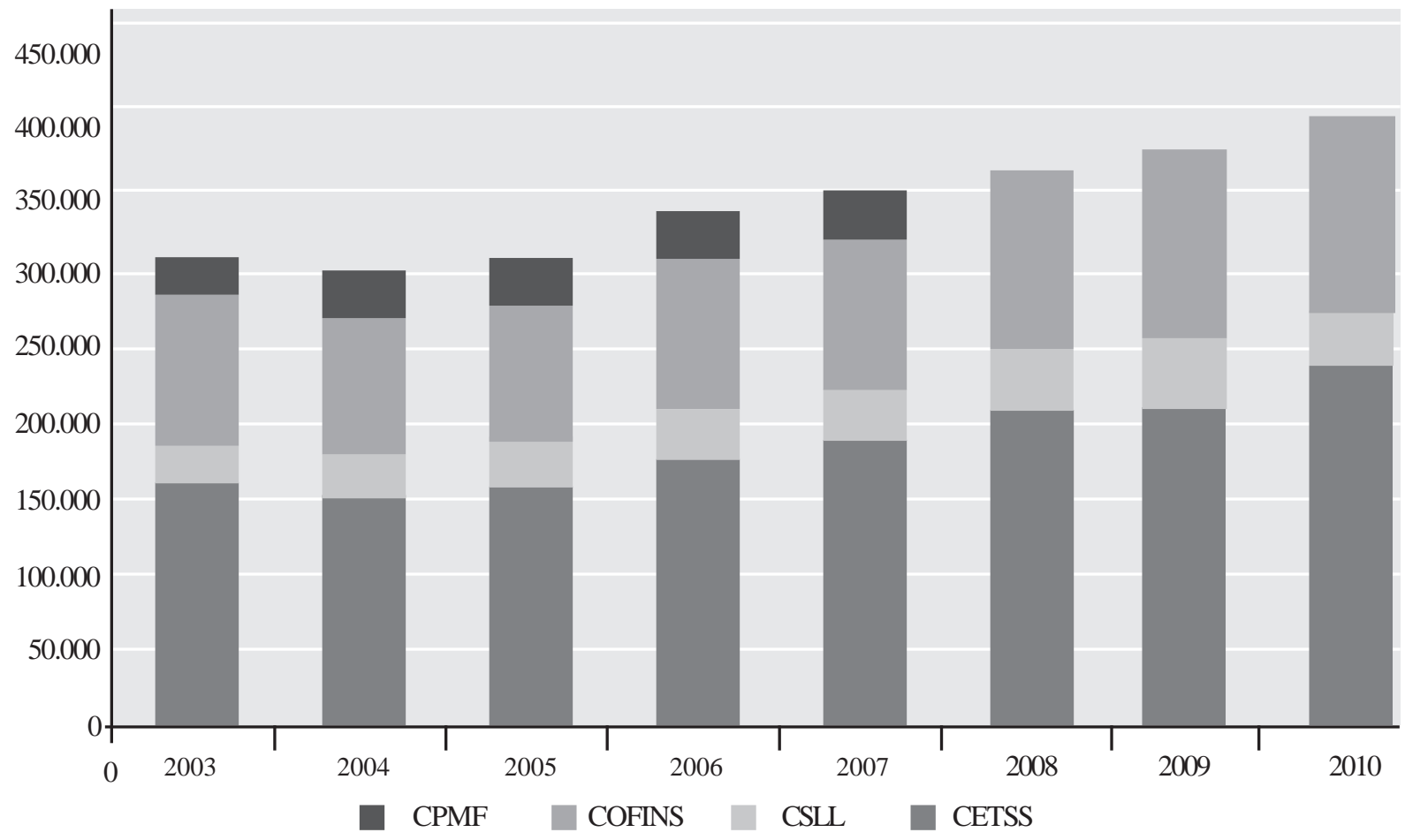

Fonte: Salvador (2012). Elaboração dos autores

Entre as contribuições sociais mais significativas estão a Contribuição dos Empregadores e Trabalhadores para a Seguridade Social (CETSS), que representou 51,6\% do total, a Contribuição para o Financiamento da Seguridade Social (COFINS), 29,09\%, a Contribuição Social sobre o Lucro Líquido (CSLL), 9,21\% e a Contribuição Provisória sobre Movimentação Financeira (CPMF), 4,89\%.

O gráfico 2 demonstra as receitas advindas das CETSS para ao financiamento da seguridade social.

Gráfico 2 - Receita da CETSS por contribuição dos trabalhadores, empregadores e outras contribuições no período 2003-2010, em $\mathbf{R} \$$ milhões constantes, deflacionados pelo IGP-DI

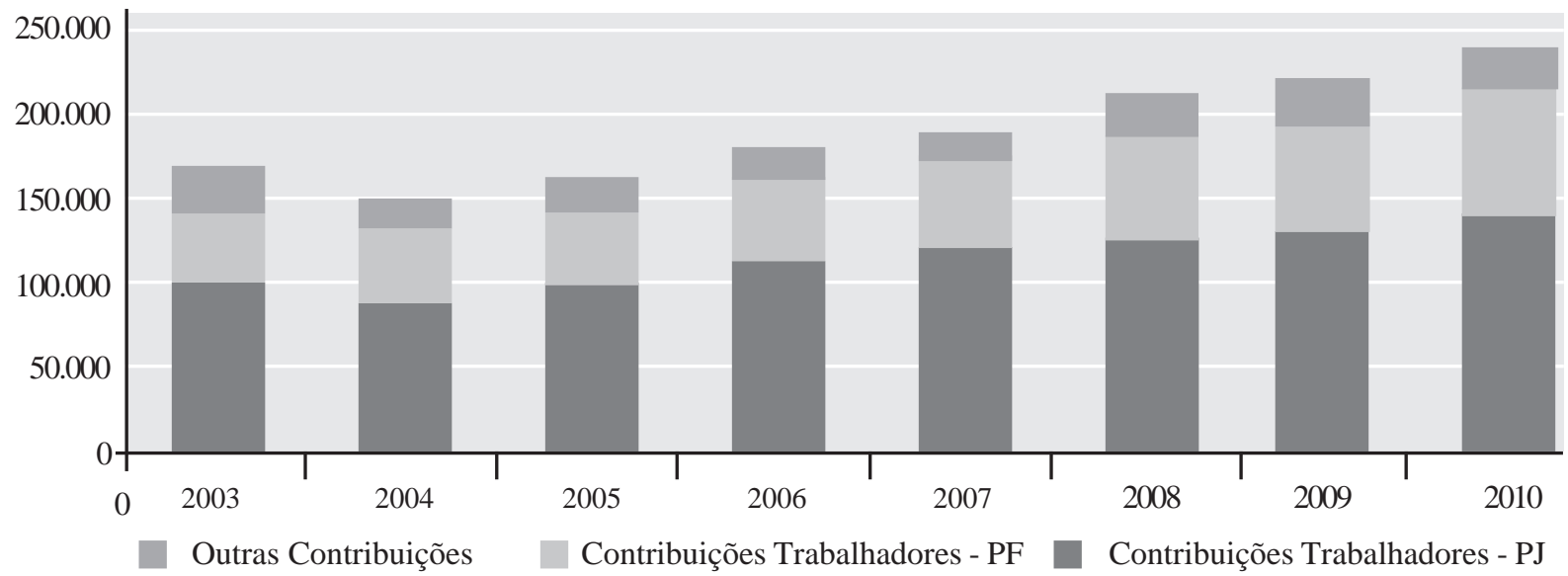

Fonte: Salvador (2012). Elaboração dos autores. 
Em 2003, a CETSS, principal contribuição social e que incide sobre a folha de pagamento das empresas e da contribuição direta dos trabalhadores para a previdência social, arrecadou para o financiamento da previdência social R \$ 159.406 milhões, sendo que R \$ 100.054 milhões foram aportados pela contribuição dos empregadores, R \$ 41.546 milhões foram pelas contribuições dos trabalhadores e R \$ 17.805 milhões por outras contribuições previdenciárias. Em 2010, as contribuições atingiram R \$ 236.990 milhões, sendo que R \$ 138.620 milhões oriundos dos empregadores, $\mathrm{R} \$ 80.747$ milhões dos trabalhadores e R $\$ 17.622$ milhões de outras contribuições.

Portanto, do ponto de vista das contribuições dos empregadores e trabalhadores para o financiamento da previdência no governo Lula (2003-2013), ficou evidente um crescimento de 48,67\% na CETSS influenciada mais pelo crescimento das contribuições dos trabalhadores $(94,36 \%)$ do que pelo crescimento das contribuições dos empregadores $(38,55 \%)$, muito embora os encargos pagos pelos patrões ainda serem a principal fonte de recursos da CETSS. Ressalva-se que essa fonte de financiamento está em risco nos anos recentes, devido à chamada desoneração da Folha de Pagamento. Os gastos tributários advindos da desoneração da folha de pagamento alcançaram o montante de $\mathrm{R} \$ 24$ bilhões em 2014, representando mais da metade das desonerações alocadas na função trabalho e 9,64\% dos gastos tributários previstos no Projeto de Lei Orçamentária (Ploa) de 2014 (RFB, 2013). Essas desonerações da folha de pagamento afetam diretamente o Orçamento da Seguridade Social (OSS), pois a Contribuição de Empregados e Empregadores, que integra a contribuição sobre a folha de pagamento, representa mais da metade do OSS (SALVADOR, 2015).

O governo federal incluiu no âmbito do plano Brasil Maior, lançado em agosto de 2011, a desoneração da folha de pagamento para alguns segmentos econômicos (confecção, calçados, móveis e softwares), que será compensada no faturamento desses segmentos. Diante do agravamento da crise econômica internacional, essas medidas foram ampliadas em 2012 (SALVADOR, 2015). Em abril de 2012, ampliaram-se as desonerações tributárias por meio da substituição da contribuição previdenciária patronal sobre a fo-

.. diante de um cenário de financeirização do capital e do ajuste neoliberal do Estado brasileiro, que se configurou antes e durante o governo Lula, o fundo público cumpriu seu papel histórico, na atual fase do capitalismo, de servir mais ao capital do que aos trabalhadores. lha de pagamento ( $20 \%$ do INSS) de 15 setores da indústria por uma alíquota entre $1,5 \%$ e $2,5 \%$ sobre o faturamento bruto das empresas. De acordo com o Ministério da Fazenda, somente esta renúncia é estimada em $\mathrm{R} \$ 7,2$ bilhões ${ }^{2}$. Isso ocorre porque a mudança de base da contribuição da folha de pagamento para uma alíquota sobre a receita bruta das empresas foi fixada em um patamar inferior à cobrada sobre a folha de pagamento. A desoneração da folha de pagamento foi sendo ampliada, alcançando, em janeiro de 2014,56 segmentos da economia (dos setores de indústria, serviços, transportes, construção e comércio).

A COFINS, segunda contribuição social mais importante e que incide sobre o faturamento das empresas, aportou recursos na ordem de R \$ 97.225 milhões para o financiamento da saúde e da assistência social em 2003. Esses recursos sofreram uma queda nos dois anos seguintes do governo Lula para voltar a crescer em 2006 e atingir o teto de R\$ 119.829 milhões em 2008 e encerar o período com R \$ 115.984 milhões em 2010 , como pode ser visualizado no Gráfico 1. Crescimento de 19,29\%, a menor taxa entre as contribuições sociais mais importantes na comparação dos anos 2003 e 2013.

A CSLL, a terceira contribuição social mais importante e a única que incide sobre a renda do capital, aportou recursos na ordem de $\mathrm{R}$ \$ 24.289 milhões para o financiamento da saúde e da assistência social em 2003. Esses recursos sofreram uma queda no ano subsequente, voltaram a crescer em 2006 e atingiram o teto de $\mathrm{R} \$ 46.258$ milhões em 2009 e recuaram para $\mathrm{R} \$ 39.374$ milhões em 2010. Crescimento de $62,11 \%$ no período analisado, sendo a maior taxa entre todas as contribuições sociais. No entanto quando se analisa a participação da CSLL no total das contribuições sociais, ela praticamente não se altera, variando de $8 \%$ em 2003 para $9 \%$ em 2013.

A CPMF, contribuição sobre a movimentação financeira e fonte de recursos importante para o financiamento da saúde no governo Lula até 2007, aportou recursos para a seguridade social da ordem de R\$27.119 milhões, em 2003. Em 2007, último ano de vigência, foi arrecadado R \$ 31.100 milhões, 8\% do total de recursos arrecadados pelas contribuições sociais. Sua extinção reduziu as fontes de recursos estáveis ${ }^{3}$ e levou ao governo buscar outras fontes, agora instáveis, como as receitas financeiras, operações de crédito e compensação financeira do petróleo. Estas fontes não foram criadas para financiar a seguridade social, por isso poderão 
ser alocadas para quaisquer despesas tributárias, o que coloca o financiamento das políticas sociais mais dependente da disputa política a ser travada no orçamento fiscal.

Portanto, no governo Lula, ficou demonstrado que as contribuições sociais representaram, em média, 89\% das receitas arrecadadas para o financiamento da seguridade social. Destas, a CETSS participa com $51 \%$, a COFINS com 29\% e a CSLL com 9\%. No entanto, a extinção da CPMF e a necessidade de novas fontes para o financiamento da seguridade social fizeram o governo substituir fontes estáveis por fontes instáveis colocando em risco a estabilidade do financiamento das políticas e os efeitos redistributivos que elas podem produzir no âmbito da sociedade brasileira.

\section{Considerações finais}

Este artigo demonstrou os efeitos produzidos pela hegemonia neoliberal da finança sobre o financiamento da política pública de seguridade social, no governo Lula, a partir da análise da execução do orçamento público federal segundo suas fontes de recursos, permitindo fazer algumas constatações: o governo Lula deu continuidade ao caráter regressivo do financiamento das políticas de seguridade social do governo anterior, onerando fiscalmente os trabalhadores e as classes de menores rendas e privilegiando os capitalistas, principalmente, os da fração superior das classes capitalistas.

No que diz respeito às fontes de financiamento da seguridade social, as contribuições sociais foram as mais representativas. Aportaram R $\$ 361$ bilhões por ano, o que significou uma participação média de $89 \%$ desta fonte no total de recursos anual no período de 2003-2010. Entre as contribuições sociais, a CETSS, fonte de financiamento exclusivo da previdência, foi a mais representativa, seguida pela COFINS e CSLL. Na primeira, os empregadores são, em termos absolutos, os maiores contribuintes da previdência, mas em termos relativos, houve um crescimento mais acelerado das contribuições dos trabalhadores em relação aos empregadores no governo Lula. Isto implica em dizer que houve uma desaceleração dos gastos dos empregadores e uma aceleração dos gastos dos trabalhadores com a previdência social. Além disso, a contribuição dos empregadores tem um caráter de tributo indireto, já que eles contabilizam como custo o seu gasto contributivo e repassam para os preços dos produtos a serem consumidos, transferindo para os consumidores o ônus tributário, anulando o efeito redistributivo e ampliando a regressividade da tributação.

A COFINS, segunda fonte mais representativa das contribuições sociais que incide sobre o faturamento e as receitas das empresas, também se configura como um tributo indireto e regressivo, pois repassa o ônus tributário dos empresários no momento do faturamento dos produtos para os trabalhadores consumidores, mais uma vez anulando o gasto tributário realizado e transferindo-o para os trabalhadores, principalmente, para aqueles de rendas mais baixas.

Por último, a CSLL, a única contribuição que incide sobre a renda dos capitalistas, não teve sua posição alterada em termos de participação no total arrecadado pelas contribuições sociais no governo Lula. No entanto, ao comparar as receitas médias geradas pela incidência das contribuições sobre a renda dos capitalistas (CSLL) e dos trabalhadores (contribuições para a previdência) é possível afirmar que as rendas geradas pelas contribuições dos trabalhadores é 1,7 vezes superior às contribuições geradas pelos capitalistas empresariais. O que implica em dizer que a renda do capital (lucro) gerou, proporcionalmente, menos recursos tributários do que a renda dos trabalhadores destinada ao pagamento da sua previdência.

Portanto, diante de um cenário de financeirização do capital e do ajuste neoliberal do Estado brasileiro, que se configurou antes e durante o governo Lula, o fundo público cumpriu seu papel histórico, na atual fase do capitalismo, de servir mais ao capital do que aos trabalhadores. O que foi demonstrado pela estrutura tributária que se apoiou em tributos sobre o consumo e a produção de caráter indireto e regressivo para arrecadar recursos e financiar as políticas de seguridade social no Brasil.

\section{Referências}

AGLIETTA, M. Macroeconomia financeira: mercado financeiro, crescimento e ciclos. São Paulo: Loyola, 2004.

BEHRING, E. R. Crise do capital, fundo público e valor. In: BOSCHETTI, I.; BEHRING, E. R.; SANTOS, S. M. M; MIOTO, R. C.

T. (Orgs.). Capitalismo em crise, política social e direitos. São Paulo: Cortez, 2010.

. Brasil em contrarreforma: desestruturação do Estado e perda de direitos. São Paulo: Cortez, 2008.

BEHRING, E. R.; BOSCHETTI, I. (Orgs.). Capitalismo em crise, política social e direitos. São Paulo: Cortez, 2010. Política social: fundamentos e história. São Paulo: Cortez, 2011.

BRASIL. Constituição 1988. 21 ed. Brasília: Câmara dos Deputados, 2003. 
CAMARA, M.; SALAMA, P. O neoliberalismo sob a hegemonia norte-americana. In: Finança Mundializada: raízes sociais e políticas, configuração, consequências. Tradução de Rosa Maria Marques e Paulo Nakati. São Paulo: Boitempo, 2005.

CHESNAIS, F. A finança mundializada: raízes sociais e políticas, configuração, consequências. Tradução de Rosa Maria Marques e Paulo Nakati. São Paulo: Boitempo, 2005.

CHESNAIS, F. A mundialização do capital. Tradução: Silvana Finzi Foá. São Paulo: Xamã, 1996.

DUMÉNIL, G.; LÉVY, D. O neoliberalismo sob a hegemonia norte-americana. In: CHESNAIS, François (org.). A finança mundializada: raízes sociais e políticas, configuração, conseqüências. Tradução de Rosa Maria Marques e Paulo Nakati. São Paulo: Boitempo, 2005. HARVEY, D. Condição pós-moderna. Tradução: Adail Ubirajara Sobral e Maria Stela Gonçalves São Paulo: Loyola, 1993.

MANDEL, E. O capitalismo tardio. Tradução Carlos Eduardo Silveira Matos, Dinah de Abreu Azevedo. São Paulo: Abril Cultural, 1982. . A crise do capital: os fatos e sua interpretação marxista. Tradução: Juarez Guimarães e João Machado Borges. São Paulo: Ensaios, 1990.

MARX, K. O capital: crítica da economia política. Tradução de Regis Barbosa e Flávio R. Kothe. São Paulo: Nova Cultural, 1988. (Livro Terceiro, vol. 4)

MÉSZÁROS, I. A crise estrutural do capital. Tradução Francisco Raul Cornejo. São Paulo: Boitempo, 2009.

RFB. Demonstrativo dos Gastos Tributários - PLOA 2014. Brasília: Secretaria da Receita Federal do Brasil, 2013.

SALVADOR, E. Os Impactos das Renúncias Tributárias no Financiamento das Políticas Sociais no Brasil. Brasília: INESC, 2015. . Crise do capital, fundo público e valor. In: BOSCHETTI, I.; BEHRING, E. R.; SANTOS, S. M. M; MIOTO, R. C. T. (Orgs.).

Capitalismo em Crise, Política Social e Direitos. São Paulo: Cortez, 2010.

. Financiamento tributário da política social no pós-real. In: SALVADOR, E. et al (Orgs.). Financeirização, Fundo Público e Política Social. São Paulo: Cortez, 2012.

SENADO FEDERAL. SIGA Brasil. 2003-2013. Disponível em: 〈http://www12.senado.gov.br/orcamento/sigabrasil〉. Acesso em: 28 jul. 2014.

\section{Notas}

1 A Constituição no seu art. 195, III, §2, determina que a proposta de orçamento da seguridade social seja elaborada de forma integrada pelos órgãos responsáveis pela saúde, previdência social e assistência social.

2 Conforme: <http://www.receita.fazenda.gov.br/automaticoSRFSinot/2012/04/05/2012_04_05_11_49_16_693391637.html>.

3 As contribuições sociais são fonte de recursos estáveis, pois obrigam o Estado a aplicar os recursos no destino estabelecido quando o tributo foi criado.

\section{Osmar Gomes Alencar Junior}

jrosmar@hotmail.com

Doutorando em Políticas Públicas na Universidade Federal do Maranhão (UFMA)

Professor Assistente do Departamento de Ciências Econômicas e Quantitativas do Campus Ministro Reis Velloso da Universidade Federal do Piauí (UFPI)

\section{Universidade Federal do Piauí}

Av. São Sebastião

Parnaíba, PI - Brasil

CEP: 64000-000

\section{Evilásio da Silva Salvador}

evilasiosalvador@gmail.com

Doutor em Política Social pela Universidade de Brasília (UnB)

Pós-doutor em Serviço Social pela Universidade do Estado do Rio de Janeiro (UERJ)

Professor na graduação em Serviço Social e no Programa de Pós-graduação em Política Social na Universidade de Brasília (UnB)

\section{Universidade de Brasília}

ICC Centro - Mezanino - B1-432

Asa Norte - Brasilia, DF - Brasil

CEP: 70910-900 